\title{
Preserved Fetal Plasma Amino Acid Concentrations in the Presence of Maternal Hypoaminoacidemia
}

\author{
MERCEDES DOMENECH, PHILIP A. GRUPPUSO, VINCENT T. NISHINO, JOHN B. SUSA, AND \\ ROBERT SCHWARTZ \\ Department of Pediatrics, Rhode Island Hospital, Brown University Program in Medicine, Providence, \\ Rhode Island 02902
}

\begin{abstract}
The effects on the conceptus of persistently decreased maternal plasma amino acid concentrations were studied in pregnant rats by the infusion of glucagon $(0.21$ $\mathrm{mg} /$ day) to the mother from day 14 to 20 of gestation with a subcutaneous, osmotically driven minipump. Controls received diluent. The experimental animals either had normal caloric intake and weight gain, or diminished caloric intake with no weight gain. Both experimental groups exhibited a decrease in plasma total amino acid concentration of approximately $\mathbf{5 0 \%}$. Maternal plasma glucose and insulin concentrations were unaffected except for slight decreases in the low weight gain group. At cesarean section on day 20 , fetal weight was unaffected in the normal weight gain group, while the low weight gain animals exhibited intrauterine growth retardation. Fetal plasma glucose and insulin concentrations were unaffected. Despite the marked decrease in maternal plasma total amino acid concentration, fetal plasma total amino acid concentration was unaffected. Individual plasma amino acid concentrations in the normal weight gain mothers and fetuses revealed a spectrum of changes. Some maternal amino acids were decreased by more than $60 \%$ ( $\alpha$-aminobutyric acid, asparagine, threonine, glutamine, alanine) while others were unaffected (tyrosine, tryptophan, phenylalanine, histidine). In general, amino acids that were decreased in the mother exhibited no change or a lesser decrease in fetal plasma concentration, while those that were unaffected in the mothers showed increased fetal concentrations. Fetuses from the low weight gain mothers had plasma amino acid profiles that were similar to those of the normal weight gain mothers. We speculate that the preserved fetal plasma amino acid concentrations are due to enhanced placental transport of amino acid secondary to maternal substrate decrease. (Pediatr Res 20: 1071-1076, 1986)
\end{abstract}

\section{Abbreviations}

IUGR, intrauterine growth retardation ANOVA, one-way analysis of variance

During fetal life the placenta is responsible for the transfer of nutrients to the fetus. This process is regulated by mechanisms

Received November 14, 1985; accepted June 3, 1986.

Address for reprints R. Schwartz, M.D., Department of Pediatrics, Rhode Island Hospital, Providence, RI 02902.

This work was supported in part by grants from the NIH (NICHHD-11343) and the Rhode Island Hospital Research Fund. M. D. is the recipient of a grant from the Spanish National Institute of Health. P. A. G. is the recipient of a Special Emphasis Research Career Award (NIH-AM01227). which are specific for each group of nutrients. In the case of amino acids it has been demonstrated that the placenta is capable of concentrating most amino acids intracellularly in order to achieve transport to the fetus against a concentration gradient (1-4). This results in fetal plasma amino acid concentrations which can be more than three times higher than maternal plasma concentrations $(1,5,6)$.

Maternal substrate limitation, presumably by limiting nutrient transport to the fetus, can lead to IUGR. This has been demonstrated experimentally in models utilizing starvation (7) or ligation of the uterine artery (8). These manipulations result in nonspecific reduction in the delivery of substrates, including glucose and amino acids, such that the roles of specific substrates remain obscure.

The aim of the present study was to develop a model in which maternal plasma amino acid concentrations are selectively reduced without significant changes in the maternal concentrations of other nutrients. In nonpregnant male rats, a persistent increase in glucagon has been shown to be associated with a decrease in total plasma amino acid concentrations (9). This is consistent with findings described in patients with glucagonoma syndrome $(10,11)$, and in adults $(12,13)$ and newborns (14) infused with glucagon. The model is applicable to the study of pregnant animals since glucagon is one of several polypeptide hormones that has been shown not to cross the placenta in animals $(15,16)$ and humans (17). The present study was based on the hypothesis that a continuous suppression of maternal plasma amino acid concentration would result in decreased fetal concentrations which might produce IUGR, either directly through substrate limitation and/or by impairing fetal insulin secretion $(18,19)$. Rather than confirming this hypothesis, we found a potential for augmented placental amino acid transport which is sufficient to maintain normal fetal growth in the face of severe limitation of maternal plasma amino acid concentrations.

\section{MATERIALS AND METHODS}

Twenty-four pregnant CD rats (Charles River Laboratories, Wilmington, MA) were studied. They were received on day 11 of gestation and kept in a controlled environment until the completion of the experiment. All animals were fed Purina Rat Chow (St. Louis, MO) ad libitum. Food intake and body weight were recorded daily.

On day 14 of gestation, under light ketamine anesthesia, Alzet osmotically driven minipumps (Alza 2ML2, Alza Corp., Palo Alto, CA) were implanted subcutaneously between the shoulder blades of rats weighing $259 \pm 18 \mathrm{~g}$. In 11 experimental animals the pumps were loaded with crystalline glucagon $0.85 \mathrm{mg} / \mathrm{ml}$ in $1.6 \%$ glycerol, $\mathrm{pH} 3.2$. This resulted in administration of 0.21 $\mathrm{mg} /$ day in the experimental animals. Thirteen control animals 
were treated identically except that the pumps contained only the vehicle, glycerol.

Blood was obtained without anesthesia from the tail vein prior to implantation and on days 14 and 17 , and before cesarean section on day 20 . Cesarean sections were performed on day 20 of gestation under pentobarbital anesthesia. Fetuses were exteriorized one at a time and were exsanguinated by an axillary incision with the fetoplacental unit intact. Placentas were separated from membranes, blotted dry, and weighed shortly after delivery, as were the fetal carcasses. Individual heparinized plasma samples from mothers and fetuses were analyzed.

Plasma glucose concentrations were determined by the glucose oxidase method (YSI Model 23A glucose analyzer, Yellow Springs Instrument Co., Yellow Springs, OH). Plasma immunoreactive insulin concentrations were measured by double antibody radioimmunoassay (Amersham Corp., Arlington Heights, IL) using a rat insulin standard (Eli Lilly and Co., Indianapolis, IN). Plasma immunoreactive glucagon was assayed as previously described on unextracted plasma samples using the $30 \mathrm{~K}$ antiserum (20). Total $\alpha$-amino nitrogen was determined after $\mathrm{Na}$ tungstate precipitation by the method of Satake et al. (21). Quantitative plasma amino acids were determined by a modification of the method of Lee (22) using a Dionex D-556 analyzer (Dionex Corp., Sunnyvale, CA). Samples for glucagon determination were collected into tubes containing aprotinin (Trasylol; Sigma Chemical Co., St. Louis, MO) at a final concentration of $1000 \mathrm{IU} / \mathrm{ml}$. Plasma for amino acids was deproteinized immediately with sulfosalicylic acid.

Data are expressed as mean $\pm 1 \mathrm{SD}$ or as median and range where noted. Analysis is by ANOVA and a modified Student's $t$ test. Kruskal and Wallis test was used for nonparametric data.

\section{RESULTS}

Maternal weight gain (Fig. 1 top) in the control group was 53 $\pm 11 \mathrm{~g}$ during the 6 days from implantation to delivery. The experimental animals, as had been observed in our previous study utilizing continuous glucagon excess (9), had highly variable weight gain. They were, therefore, subdivided post hoc into two nonoverlapping groups. Six animals exhibited normal weight gain over the 6 days $(46 \pm 10 \mathrm{~g})$. The remaining five experimental animals had minimal weight gain or even weight loss $(-2 \pm 13$ g) $(p<0.001)$. Caloric intake (Fig. 1 middle) was significantly reduced in this low gain weight group at $373 \pm 73 \mathrm{kcal} / 6$ day $(p$ $<0.001)$ compared to $561 \pm 55$ in the controls and $569 \pm 60$ in the normal weight gain experimental group.

Maternal plasma glucagon concentrations were elevated to supraphysiologic levels in the experimental groups at the time of cesarean section (Table 1); 690->4000 pmol/ml (median, 2800; $\mathrm{p}<0.001$ ) for the experimental animals with normal weight gain and 570->4,000 pmol/ml (median, 2700; $p<0.01$ ) for the low weight gain group versus $180-620 \mathrm{pmol} / \mathrm{ml}$ (median, 385) in the control animals.

Maternal total plasma $\alpha$-amino nitrogen concentration (Fig. 2 top) was comparable in the three groups before glucagon administration: $3.51 \pm 0.6 \mathrm{mM}$ for controls, $3.4 \pm 0.3 \mathrm{mM}$ for experimental animals with normal weight gain, and $3.2 \pm 0.5 \mathrm{mM}$ for experimental animals with low weight gain. As expected, hyperglucagonemia was associated with a profound decrease in maternal plasma $\alpha$-amino nitrogen. On day 3 of the study, control concentration was $3.4 \pm 0.4$ versus $2.0 \pm 0.5 \mathrm{mM}(p<0.001)$ in the normal weight gain group and $1.7 \pm 0.3 \mathrm{mM}(p<0.001)$ in the low weight gain group. On day 6 , prior to cesarean section, this reduction persisted: $3.4 \pm 0.3 \mathrm{mM}$ for controls versus $1.6 \pm$ $0.2 \mathrm{mM}(p<0.001)$ in the normal weight gain group and $1.8 \pm$ $0.2 \mathrm{mM}(p<0.001)$ in the low weight gain group.

Maternal plasma glucose concentrations (Table 1) were comparable in the three groups prior to pump implantation and after 3 days of glucagon infusion. On day 20 , glucose concentrations in the experimental animals were unaffected in the normal weight
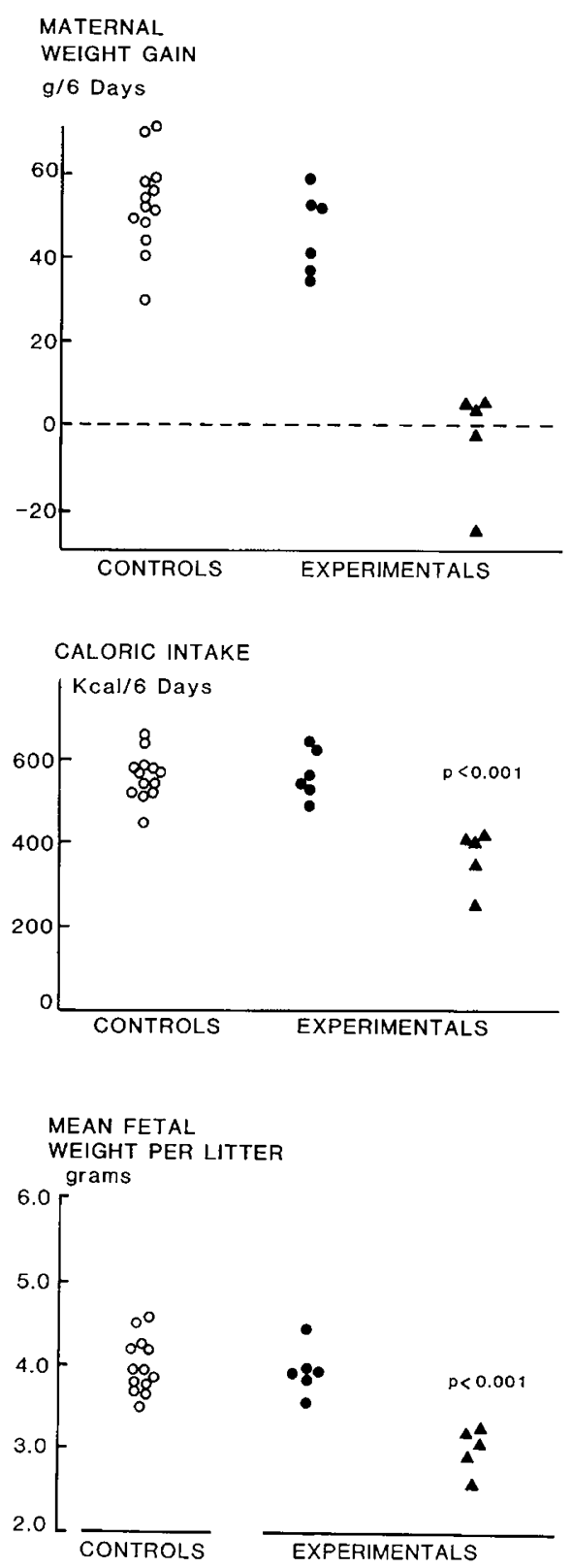

Fig. 1. Maternal weight gain (top), maternal caloric intake (middle), and mean fetal weight per litter (bottom) in experimental maternal hyperglucagonemia. Control animals are shown by open circles. Experimental animals were divided into two groups. The glucagon-treated rats (closed circles) whose weight gain over the 6-day experimental period fell within the range of control animals were designated as the normal weight gain group. In contrast, those treated animals (closed triangles) whose weight gain fell below that range were designated as the low weight gain group. Caloric intake was $33 \%$ lower in animals with low or no weight gain $(p<0.001)$.

gain group and slightly, but significantly, decreased in the low weight gain group. Maternal plasma insulin concentrations (Table 1) followed a similar pattern, with no differences between groups except for a slight decrease in the low weight gain animals.

At cesarean section, litter size was comparable in the three groups: controls, $11 \pm 2$; normal weight gain experimentals, 12 \pm 2 , and low weight gain experimentals, $12 \pm 1$.

Fetal plasma glucose concentrations (Table 1) were unaffected. Fetal insulin concentrations (Table 1) in both experimental groups were not different from controls.

Fetal weight (Fig. 1 bottom) was unaffected in the normal weight gain group $(3.95 \pm 0.30$ versus $4.01 \pm 0.33 \mathrm{~g}$ for control 
Table 1. Plasma glucose and insulin values in mothers and fetuses in all three groups

\begin{tabular}{|c|c|c|c|}
\hline & Control & Normal wt gain & Low wt gain \\
\hline \multicolumn{4}{|l|}{ Maternal } \\
\hline \multicolumn{4}{|l|}{ Plasma glucose* $(\mathrm{mg} / \mathrm{dl})$} \\
\hline Day 0 & $115 \pm 10$ & $118 \pm 10$ & $117 \pm 4$ \\
\hline Day 3 & $110 \pm 9$ & $114 \pm 6$ & $103 \pm 11$ \\
\hline Day 6 & $107 \pm 6$ & $109 \pm 7$ & $97 \pm 13 \dagger$ \\
\hline \multicolumn{4}{|l|}{ Plasma insulin $\dagger(\mathrm{uU} / \mathrm{ml})$} \\
\hline Day 0 & $9-134(64)$ & $29-176(72)$ & $30-120(53)$ \\
\hline Day 3 & $14-124(65)$ & $14-74(34.5)$ & $7-52(18) \ddagger$ \\
\hline Day 6 & $7-68(39)$ & $12-106(18)$ & $1-33(9) \S$ \\
\hline Plasma glucagon $\dagger(\mathrm{pg} / \mathrm{ml})$ & $180-620(385)$ & $690->4000(2800) \|$ & $570->4000(2700) \S$ \\
\hline \multicolumn{4}{|l|}{ Fetal } \\
\hline Plasma glucose* $(\mathrm{mg} / \mathrm{dl})$ & $66 \pm 8$ & $65 \pm 10$ & $65 \pm 8$ \\
\hline Plasma insulin $\ddagger(\mathrm{uU} / \mathrm{ml})$ & $23-450(170)$ & $31-360(128)$ & $26-435(78)$ \\
\hline
\end{tabular}

\footnotetext{
$*$ Mean \pm SD.

$\dagger$ Range (median).

$\ddagger p<0.05$ from controls.

$\S p<0.01$ from controls.

$\| p<0.001$ from controls.
}

fetuses). Fetal weight was significantly decreased in the low weight gain group at $3.03 \pm 0.29 \mathrm{~g}(p<0.001)$. Placental weight was unaffected in the two experimental groups: $263 \pm 79 \mathrm{mg}$ in the normal weight gain group and $224 \pm 31 \mathrm{mg}$ in the low weight gain group versus $228 \pm 107$ in controls.

In contrast to the marked decrease in the maternal plasma $\alpha$ amino nitrogen concentrations associated with maternal hyperglucagonemia, fetal plasma $\alpha$-amino nitrogen concentrations (Fig. 2 middle) were maintained in both experimental groups $(7.8 \pm 1.0 \mathrm{mM}$ in the normal weight gain experimental group and $8.4 \pm 1.4 \mathrm{mM}$ in the low weight gain experimental group versus $9.2 \pm 2.0$ in controls). There was, therefore, an increase in the calculated fetomaternal ratios in both experimental groups: controls, $2.6 \pm 0.5$; normal weight gain, $5.3 \pm 1.3(p<0.001$ versus controls); and low weight gain, $4.7 \pm 1.5(p<0.001)$.

Quantitative individual amino acid concentrations in maternal plasma at cesarean section for control and normal and low weight gain experimental rats (Table 2) were used to calculate the percent change from mean control concentrations (Fig. 3). The results revealed a spectrum of changes in the effects of hyperglucagonemia on individual amino acids which was similar to the results obtained previously in young male rats (9). Some amino acids exhibited profound decreases ( $\alpha$-aminobutyric acid, $71 \%$ reduction from controls; asparagine, $68 \%$; threonine, $66 \%$; glutamine and alanine, $63 \%$ ) while only tyrosine, tryptophan, phenylalanine, and histidine were unaffected. Reductions were consistent between animals and all amino acids which were decreased by more than $20 \%$ were significantly different from controls, with the exception of glutamic acid which was not significant.

The corresponding quantitative fetal plasma amino acid concentrations for normal weight gain experimental rats, expressed as percent change from the mean control concentrations (Fig. 3), exhibited a striking relationship to the maternal results. Amino acids that showed the greatest decrease in the mothers were also decreased in the fetuses. Those that were unaffected in the mothers showed a significant increase in the experimental fetuses. Amino acids for which the effects were intermediate were affected variably in the fetuses.

In the low weight gain group, the amino acid profile was very similar to the normal weight gain group with the following exceptions (See Table 2). In the maternal plasma, $\alpha$-aminobutyric acid, glycine, taurine, valine, and methionine were significantly reduced in the normal weight gain group and not in the low weight gain group. Phenylalanine, unchanged in the normal weight gain group, was significantly elevated in the low weight gain group. In fetal plasma, some amino acids that were not affected in the normal weight gain group were significantly reduced in the low weight gain group, i.e. aspartic acid, cystine, leucine, and arginine; two that were reduced in the normal weight gain group, glycine and $\alpha$-aminobutyric acid, were unchanged, as well as histidine that was significantly elevated in the normal weight gain group. Taurine and lysine, which were unchanged in the normal weight gain group, were significantly elevated in fetal plasma from mothers with low weight gain.

\section{DISCUSSION}

The primary objective of this study was to examine the effects of maternal hypoaminoacidemia on the conceptus utilizing a model of persistent maternal hyperglucagonemia. This was accomplished because there was an observed decrease in maternal plasma $\alpha$-amino nitrogen of approximately $50 \%$. The pattern of the amino acid profile in the mothers is similar to that seen in the glucagonoma syndrome $(10,11)$ with alanine and arginine being greatly reduced and phenylalanine unchanged. This is consistent with our previous findings in nonpregnant rats (9). Also accompanying the maternal hyperglucagonemia was a variable effect on food intake and weight gain. With the supraphysiologic dose of glucagon used, five of the experimental animals showed diminished food consumption and, consequently, low weight gain when compared to controls. Glucagon may exert a direct effect on appetite by functioning as a satiety signal (2325 ) or by inhibition of gastrointestinal motility (26-28). The hypothesis that the former effect is mediated through the level of glycemia (25) is not supported by either the present study or our previously published data (9). Whatever the reason for the decreased food intake, the effect was variable. This allowed the division of the experimental animals into two nonoverlapping groups, one with normal weight gain and the other with minimal weight gain or weight loss.

Maternal plasma glucose did not change in the normal weight gain experimental animals throughout the study, apart from the normal decline seen with the progression of gestation $(29,30)$. An expected decrease was seen in the low weight gain experimental animals. Fetal plasma glucose was comparable in all three groups despite maternal caloric restriction in the latter. In the mothers, plasma insulin concentrations paralleled changes in glucose concentration. By contrast, there was a slight but not significant decrease in fetal insulin concentrations in both experimental groups. In the normal weight gain group, there is no direct explanation for this effect. Although amino acids, espe- 

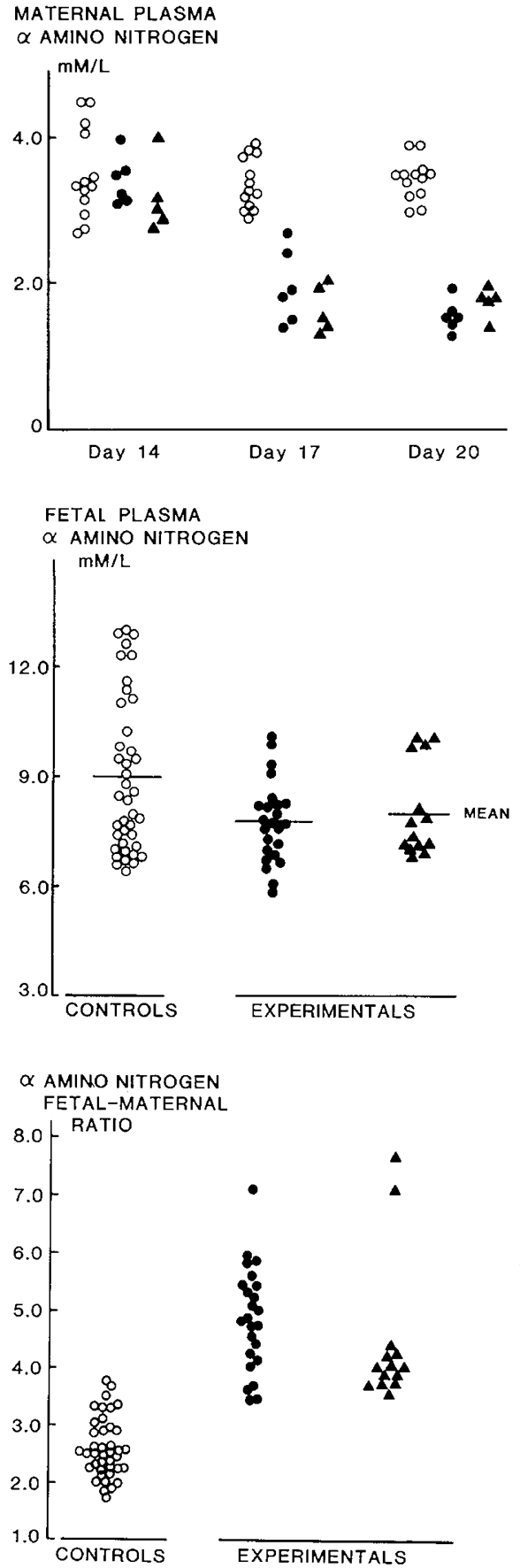

Fig. 2. (Top) Maternal plasma $\alpha$-amino nitrogen. Determinations were made on days 14, 17, and 20 of gestation. (Middle) Fetal plasma $\alpha$-amino nitrogen. (Bottom) $\alpha$-amino nitrogen fetal:maternal ratio. Each point is determined individually for a single fetus. Symbols are as described for Figure 1.

cially branched-chain amino acids, have been demonstrated to play a critical role in fetal pancreatic development (31), fetal branched-chain and total amino acid concentrations were unchanged. What cannot be ruled out is a decrease in the net flux of certain critical amino acids to the fetus. The slight decrease in fetal insulin concentration seen in the low weight gain group can be viewed similarly, although this is an expected finding based on previous studies utilizing maternal starvation (32)

Fetal weight was unaffected in the normal weight gain group despite marked maternal hypoaminoacidemia. With more general substrate limitation, as would be expected with maternal caloric deprivation, IUGR was observed, confirming the findings of others $(7,32,33)$. The absence of IUGR in the normal weight

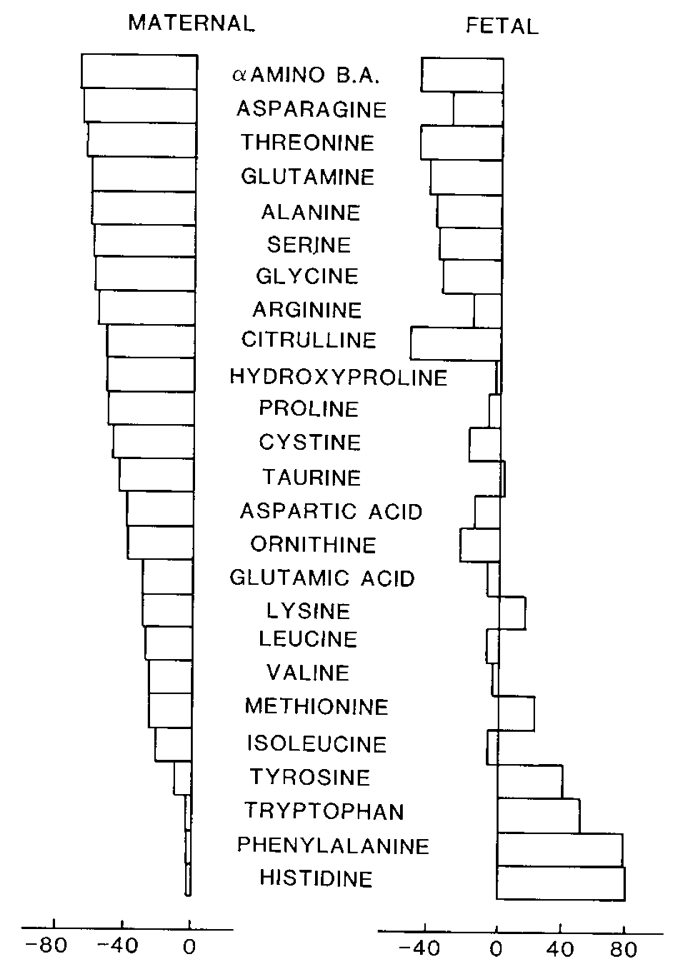

Fig. 3. Maternal and fetal plasma amino acid profiles in experimental maternal hypoaminoacidemia. The bars represent the percent change of plasma concentrations from individual experimental normal weight gain animals compared to mean control values. Amino acids were arranged in the order from most affected to least affected in maternal plasma (top to bottom).

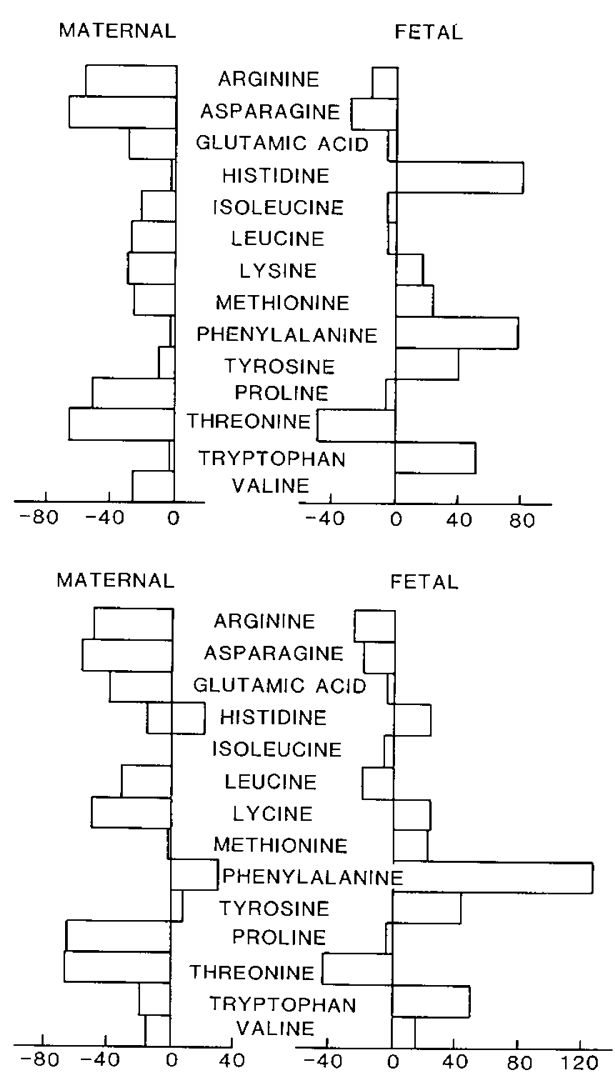

Fig. 4. Maternal and fetal plasma essential amino acids in normal weight gain rats (upper panel) and low weight gain rats (lower panel) expressed as percent change from controls. 
Table 2. Plasma amino acids ( $\mu$ mol/liter) in mothers and fetuses with normal weight gain (NWG), low weight gain (LWG), and controls (mean $\pm S D)$

\begin{tabular}{|c|c|c|c|c|c|c|}
\hline & \multicolumn{3}{|c|}{ Maternal } & \multicolumn{3}{|c|}{ Fetal } \\
\hline & \multirow[b]{2}{*}{ Control } & \multicolumn{2}{|c|}{ Experimental } & \multirow[b]{2}{*}{ Control } & \multicolumn{2}{|c|}{ Experimental } \\
\hline & & NWG & LWG & & NWG & LWG \\
\hline Taurine & $175 \pm 43$ & $96 \pm 26$ & $209 \pm 98$ & $361 \pm 63$ & $371 \pm 66$ & $515 \pm 173^{*}$ \\
\hline Aspartic acid & $16 \pm 2$ & $9 \pm 2 \dagger$ & $10 \pm 2 *$ & $35 \pm 8$ & $30 \pm 4$ & $21 \pm 6 \dagger$ \\
\hline Hydroxyproline & $52 \pm 10$ & $25 \pm 7 \dagger$ & $22 \pm 8^{*}$ & $144 \pm 27$ & $147 \pm 34$ & $154 \pm 30$ \\
\hline Threonine & $288 \pm 34$ & $99 \pm 40 \dagger$ & $93 \pm 27 \dagger$ & $369 \pm 72$ & $188 \pm 90 \dagger$ & $208 \pm 50 \dagger$ \\
\hline Serine & $287 \pm 39$ & $111 \pm 27 \dagger$ & $127 \pm 22 \dagger$ & $489 \pm 45$ & $308 \pm 99 \dagger$ & $344 \pm 72 \dagger$ \\
\hline Asparagine & $77 \pm 13$ & $24 \pm 3 \dagger$ & $32 \pm 7 \uparrow$ & $126 \pm 24$ & $89 \pm 26^{*}$ & $102 \pm 30 \S$ \\
\hline Glutamic acid & $60 \pm 19$ & $42 \pm 20$ & $36 \pm 8$ & $115 \pm 40$ & $108 \pm 35$ & $111 \pm 45$ \\
\hline Glutamine & $603 \pm 56$ & $221 \pm 14 \uparrow$ & $167 \pm 22 \dagger$ & $1119 \pm 172$ & $643 \pm 122 \dagger$ & $487 \pm 98+$ \\
\hline Proline & $226 \pm 34$ & $108 \pm 19 \dagger$ & $75 \pm 26 \dagger$ & $350 \pm 71$ & $325 \pm 80$ & $332 \pm 106$ \\
\hline Glycine & $162 \pm 32$ & $64 \pm 17 \dagger$ & $122 \pm 18$ & $388 \pm 75$ & $257 \pm 115 \dagger$ & $345 \pm 67$ \\
\hline Alanine & $619 \pm 97$ & $231 \pm 45 \dagger$ & $251 \pm 77 \dagger$ & $1231 \pm 277$ & $768 \pm 216 \dagger$ & $873 \pm 163 \dagger$ \\
\hline Citrulline & $58 \pm 12$ & $27 \pm 3 \dagger$ & $14 \pm 4 \dagger$ & $43 \pm 14$ & $20 \pm 3 \dagger$ & $19 \pm 9 \dagger$ \\
\hline$\alpha$-Amino butyric acid & $18 \pm 8$ & $5 \pm 2$ & $9 \pm 10$ & $49 \pm 12$ & $25 \pm 12 \dagger$ & $39 \pm 18$ \\
\hline Valine & $125 \pm 9$ & $92 \pm 17^{*}$ & $106 \pm 10$ & $424 \pm 69$ & $414 \pm 105$ & $487 \pm 130$ \\
\hline Cystine & $43 \pm 5$ & $22 \pm 6 \dagger$ & $29 \pm 4 \ddagger$ & $29 \pm 9$ & $24 \pm 9$ & $19 \pm 7 \ddagger$ \\
\hline Methionine & $40 \pm 4$ & $30 \pm 1 \dagger$ & $39 \pm 15$ & $147 \pm 17$ & $181 \pm 24 \S$ & $180 \pm 60 \S$ \\
\hline Isoleucine & $69 \pm 5$ & $54 \pm 7^{*}$ & $58 \pm 6 \S$ & $183 \pm 27$ & $174 \pm 50$ & $185 \pm 61$ \\
\hline Leucine & $122 \pm 10$ & $88 \pm 12 \dagger$ & $82 \pm 16^{*}$ & $353 \pm 63$ & $331 \pm 105$ & $282 \pm 86 \S$ \\
\hline Tyrosine & $40 \pm 7$ & $36 \pm 8$ & $43 \pm 8$ & $244 \pm 70$ & $342 \pm 57 \dagger$ & $349 \pm 58 \dagger$ \\
\hline Phenylalanine & $62 \pm 5$ & $60 \pm 8$ & $80 \pm 8 \ddagger$ & $327 \pm 43$ & $581 \pm 98 \dagger$ & $744 \pm 138 \dagger$ \\
\hline Tryptophan & $64 \pm 8$ & $63 \pm 12$ & $52 \pm 14$ & $162 \pm 28$ & $244 \pm 32 \dagger$ & $242 \pm 46 \dagger$ \\
\hline Ornithine & $48 \pm 6$ & $29 \pm 8^{*}$ & $16 \pm 5 \dagger$ & $65 \pm 11$ & $50 \pm 11^{*}$ & $46 \pm 13 \dagger$ \\
\hline Lysine & $727 \pm 91$ & $506 \pm 132 \ddagger$ & $351 \pm 55 \dagger$ & $1509 \pm 351$ & $1760 \pm 248$ & $1865 \pm 346 \S$ \\
\hline Histidine & $30 \pm 6$ & $29 \pm 5$ & $36 \pm 6$ & $81 \pm 36$ & $145 \pm 52 \dagger$ & $100 \pm 92$ \\
\hline Arginine & $150 \pm 21$ & $88 \pm 9 \dagger$ & $74 \pm 20^{*}$ & $212 \pm 44$ & $177 \pm 45$ & $159 \pm 45 \ddagger$ \\
\hline$\Sigma$ Essential amino acid & $2081 \pm 155$ & $1317 \pm 209 \dagger$ & $1158 \pm 183 \dagger$ & $4602 \pm 704$ & $5061 \pm 637$ & $5354 \pm 924 \S$ \\
\hline
\end{tabular}

gain experimental group is interpreted as indicating a compensatory mechanism which, based on our results, is probably intrinsic to the placenta. Despite a net decrease of approximately $50 \%$ in maternal total amino acid concentration, fetal total amino acid concentration was unchanged. This could be due to decreased fetal amino acid utilization, although this seems unlikely in the absence of IUGR. A more tenable hypothesis is that placental transport of amino acids increased such that availability to the fetus was maintained. Such an increase in transport could be secondary to increased placental blood flow or induction of placental amino acid transport systems.

The essential amino acids for the growing rat are the same as for man, with the addition of arginine, asparagine, glutamic acid, proline, and tyrosine (34). In Figure 4 we have represented how the essential amino acids are affected in both the normal weight gain group (upper panel) and low weight gain group (lower panel). Two amino acids that are greatly reduced in the mother, asparagine and threonine, are reduced the most in the fetal plasma in the normal weight gain group. Arginine and proline reduced in the mothers are unchanged in the fetal plasma. Amino acids with moderate reduction in maternal plasma do not change in fetal plasma, but those not reduced in the maternal plasma are generally present in higher concentrations in the fetal plasma.

The low weight gain group exhibits subtle differences from the normal weight gain group. It is important to note that this group has only partial self-deprivation for food, rather than total starvation. This $33 \%$ reduction of intake resulted in a decrease in the fetal weight. The amino acid pattern did not resemble that described in rats which were subjected to $96 \mathrm{~h}$ of starvation (32). In the latter, maternal plasma amino acid concentrations of some essential (branch chain, histidine) and nonessential (taurine, ornithine) amino acids are highly augmented. The concentration of these amino acids are concomitantly increased in the fetuses with the exception of histidine that is reduced and valine that is only moderately elevated. Although threonine has been postulated to play an important role in fetal growth retardation (35), in our studies threonine was reduced approximately $50 \%$ in both groups, the normal and low weight gain, only one of which had IUGR.

The present model uniquely dissociates maternal plasma substrate concentrations in contrast to prolonged maternal starvation which affects multiple nutrients. Chronic administration of glucagon produced persistent low maternal plasma amino acids without affecting plasma glucose concentrations. Furthermore, fetal glucose and insulin concentrations were unaffected. It is unlikely that the glucagon or maternal amino acid changes affect placental blood flow. The preserved fetal amino acid concentrations must be secondary to enhanced placental transfer. Studies in other tissues have shown increased cellular uptake and transport of amino acids to be substrate-dependent (36). We speculate that a similar process occurs in placental cells.

Acknowledgments. The authors thank Dr. Michael D. Caldwell and Mr. Balduino Mastrofrancesco for their assistance with specific amino acid analyses and Dr. Caldwell for his review of the manuscript. Our thanks to Mrs. Theresa Bienieki and Mrs. Kathleen Petzold for their technical assistance, Mrs. Donna M. Berger for her expert manuscript preparation, and Ms. Patricia Hatch for the graphic designs. Crystalline glucagon was kindly provided by Dr. Mary Root, Eli Lilly and Co., Indianapolis, IN. $30 \mathrm{~K}$ antiserum was obtained from Dr. R. H. Unger, Dallas, TX.

\section{REFERENCES}

1. Hill PMM, Young M 1973 Net placental transfer of free amino acids against varying concentrations. J Physiol (Lond) 235:409-422 
2. Schneider H, Dancis J 1974 Amino acid transport in human placental slices. Am J Obstet Gynecol 120:1092-1097

3. Philipps AF, Holzman IA, Teng C, Battaglia FC 1978 Tissue concentrations of free amino acids in term human placentas. Am J Obstet Gynecol 131:811887

4. Smith CH, Adcock EW, Teasdale F, Meschia G, Battaglia C 1973 Placental amino acid uptake: tissue preparation, kinetics and preincubation effect. Am J Physiol 224:558-564

5. Christensen HN, Streicher JA 1948 Association between rapid growth and elevated cell concentrations of amino acids. I. In foetal tissues. J Biol Chem 175:95-100

6. Dancis J, Money WL, Springer D, Levitz M 1968 Transport of amino acids by placenta. Am J Obstet Gynecol 101:820-829

7. Chow BF, Lee C-J 1964 Effect of dietary restriction of pregnant rats on body weight gain of the offspring. $J$ Nutr $82: 10-18$

8. Wigglesworth JS 1964 Experimental growth retardation in the feotal rat. J Pathol Bact $88: 1-13$

9. Gruppuso PA, Susa JB, Domenech M, Cha C-J, Schwartz R 1983 Chronic hyperglucagonemia in rats: effects on insulin, substrates and hepatic enzymes of intermediary metabolism. Metabolism 32:911-918

10. Mallinson CN, Bloom SR, Warin AP, Salmon PR, Cox B 1974 A glucagonoma syndrome. Lancet $2: 1-5$

11. Boden G, Owen OE, Rezvani I, Elfenbein BI, Quickel KE 1977 An islet cell carcinoma containing glucagon and insulin. Diabetes 16:128-137

12. Landau RL, Lugibihl K 1969 Effect of glucagon on concentration of several free amino acids in plasma. Metabolism 18:265-276

13. Boden G, Rezvani I, Owen OE 1984 Effects of glucagon on plasma amino acids. $\mathrm{J}$ Clin Invest 73:785-793

14. Reisner SH, Aranda JV, Colle E, Papageorgio A, Schiff D, Scriver CR, Stern L 1973 The effect of intravenous glucagon on plasma amino acids in the newborn. Pediatr Res 7:184-191

15. Alexander DP. Assan R, Gritton HG, Nixon DA 1973 Impermeability of the sheep placenta to glucagon. Biol Neonate 23:391-402

16. Girard JR, Kervran A, Soufflet E, Assan R 1974 Factors affecting the secretion of insulin and glucagon by the rat fetus. Diabetes 23:310-317

17. Adam PAJ, King KC, Schwartz R, Teramo K 1972 Human placental barrier to ${ }^{125}$ I-glucagon early in gestation. J Clin Endocrinol 34:772-782

18. Kervran A, Randon J 1980 Development of insulin release by fetal rat pancreas in vitro: effects of glucose, amino acids and theophylline. Diabetes 29:673678

19. Milner RDG 1979 Amino acids and beta cell growth in structure and function In: Merkatz IR, Adam PAJ (eds) The Diabetic Pregnancy. A Perinatal Perspective. Grune \& Stratton, New York, pp 145-153

20. Faloona GR, Unger RH 1974 Glucagon. In: Jaffe BM, Behrman HE (eds) Methods of Hormone Radioimmunoassay. Academic Press, New York, pp $317-330$
21. Satake K, Okuyama T, Ohashi M, Shinoda T 1960 The spectrophotometric determination of amine, amino acid and peptide with 2.4.6-trinitrobenzene1-sulfonic acid. J Biochem 47:654-660

22. Lee PL 1974 Single column system for accelerated amino acid analysis of physiological fluids using five lithium buffers. Biochem Med 10:107-121

23. Geary N, Langham W, Scharrer E 1981 Metabolic concomitants of glucagoninduced suppression of feeding in the rat. Am J Physiol 241:R330-335

24. Martin JR, Novin D 1977 Decreased feeding in rats following hepatic portal infusion of glucagon. Physiol Behav 19:461-464

25. Langhans W, Zieger U, Scharrer E, Geary N 1982 Stimulation of feeding in rats by intraperitoneal injection of antibodies to glucagon. Science 218:894896

26. Stunkard AJ, Van Itallie TB, Reis BB 1955 The mechanism of satiety: effect of glucagon on gastric hunger contractions in man. Proc Soc Exp Biol Med 89:258-261

27. Chernish SM, Miller RE, Rosenak BD, Scholz NE 1972 Hypotonic duodenography with the use of glucagon. Gastroenterology 62:392-398

28. Penick SB, Hinkle LE Jr 1961 Depression of food intake induced in healthy subjects by glucagon. N Engl J Med 264:893-897

29. Watts C, Gain K, Sandin PL 1976 Glucose homeostasis in the developing rat I. Blood glucose and immunoreactive insulin in the later stages of gestation of the fetal rat. Biol Neonate 30:88-94

30. Herrera E, Knopp RH, Freinkel N 1969 Carbohydrate metabolism in pregnancy. VI. Plasma fuels, insulin, liver composition, gluconeogenesis, and nitrogen metabolism during late gestation in the fed and fasted rat. $\mathrm{J}$ Clin Invest 48:2260-2272

31. Milner RDG, Ashworth MA, Barson AJ 1972 Insulin release from human foetal pancreas in response to glucose, leucine, and arginine. J Endocrinol 52:497-505

32. Girard JR, Ferre P, Gilvert M, Kervran A, Assan R, Marliss EB 1977 Fetal metabolic response to maternal fasting in the rat. Am J Physiol 232:E456463

33. Levitsky LL, Kimber A, Marchichow A, Euhara J 1977 Metabolic response to fasting in experimental intrauterine growth retardation induced by surgical and nonsurgical maternal stress. Biol Neonate 31:311-315

34. Nutrient requirements of the laboratory rat. In: Nutrient Requirements of Laboratory Animals, 3rd ed., 1978. National Academy of Sciences, Washington, DC, p 23

35. Metcoff J, Cole TJ, Luff R 1981 Fetal growth retardation induced by dietary imbalance of threonine and dispensable amino acids, with adequate energy and protein equivalent intakes, in pregnant rats. J Nutr 111:1411-1424

36. Shotwell MA, Mattes PM, Jayme DW, Oxender DL 1982 Regulation of amino acid transport system $\mathrm{L}$ in Chinese hamster ovary cells. J Biol Chem 257:2974-2980 